\title{
Fault geometry of the 2004 off the Kii peninsula earthquake inferred from offshore pressure waveforms
}

\author{
Hiroyuki Matsumoto ${ }^{1}$ and Hitoshi Mikada ${ }^{2}$ \\ ${ }^{1}$ Deep-Sea-Research Program, IFREE, Japan Agency for Marine-Earth Science and Technology, 2-15 Natsushima, Yokosuka 237-0061, Japan \\ ${ }^{2}$ Department Civil and Earth Resources Engineering, Kyoto University, Yoshida-hommachi, Sakyo-ku, Kyoto 606-8501, Japan
}

(Received November 30, 2004; Revised February 4, 2005; Accepted February 7, 2005)

\begin{abstract}
We could successfully obtain water pressure fluctuations after a series of two off the Kii peninsula earthquakes that took place on September 5 in 2004, using two pressure gauges deployed at deep ocean-bottom off Muroto. The earthquakes caused two tsunamis in the southern coast of the southwestern Japan with maximum wave heights of $0.9 \mathrm{~m}$, and we could identify the tsunami signals from the acquired dataset ca. 20 min before the arrivals of the tsunamis to the coastline nearest to the sensors. Two earthquakes are assumed as one for a foreshock and the other for a main-shock. Although seismological studies, without aftershock distributions, showed a lack of constraints to distinguish if the main-shock was caused by either southwest dipping fault or by the other, i.e., northeast dipping fault, we found that the difference in the pressure fluctuations for the tsunamis could attribute to the determination of the fault plane in the fault models. In this paper, we evaluate the fault geometry of the main shock by using tsunami waveforms obtained by those unique instruments in following procedure: (1) We first simulate pressure waveforms caused by earthquakes of the two fault geometries, one for southwest dipping place and the other for the northeast, at the location of the pressure gauges, and (2) we then compare the simulated results with observed waveforms. Our results demonstrate that the main-shock should be caused by a fault whose strike lies in northwest-to-southeast with a dip towards southwest direction.
\end{abstract}

Key words: The 2004 off the Kii peninsula earthquake, pressure gauge, tsunami, seismic fault.

\section{Introduction}

In order to better understand the characteristics of megathrust earthquakes and spawned tsunamis at subduction zones, the Japan Agency for Marine-Earth Science and Technology (JAMSTEC) has developed and deployed two cabled ocean-bottom observatories since 1997. One has been installed in the southern Kuril subduction zone, which successfully recorded the off Tokachi earthquake in 2003 (Watanabe et al., 2004). The other has been deployed off Muroto at the western Nankai subduction zone, which consists of two ocean-bottom seismometers, two pressure gauges (PGs), and a cable-end station. A major earthquake took place off Kii Peninsula at 14:57:18 UTC on 5 September 2004 with its moment magnitude Mw of 7.4 preceded by a Mw 6.9 fore-shock at 10:07:08 UTC. Both earthquakes triggered tsunamis, which propagated to the Pacific coast from Izu islands to the Shikoku region with their recorded maximum wave heights of $0.9 \mathrm{~m}$ at Kozu Island located north-eastward from the source. A few thousands people evacuated because of two tsunami warnings issued by the Japan Metrological Agency (JMA). The earthquakes occurred in a region where the probability of forthcoming Tonankai earthquake could take place in the next 50 years is estimated as $80-90 \%$ by the Headquarters for Earthquake Research Promotion of Japanese Earthquake

Copy right(c) The Society of Geomagnetism and Earth, Planetary and Space Sciences (SGEPSS); The Seismological Society of Japan; The Volcanological Society of Japan; The Geodetic Society of Japan; The Japanese Society for Planetary Sciences; TERRAPUB
Research Committee. The two pressure gauges of the cabled observatory off Muroto have recorded water pressure fluctuations during the fore- and the main-shocks.

The focal mechanism of the fore-shock indicates a thrust faulting striking NE-SW direction that is parallel to the trough axis, while that of main-shock indicates NW-SE direction that is normal to the trough axis (Yamanaka, 2004). Both shocks took place in the subducting Philippine Sea Plate, and the locations indicate that this series of earthquakes were of intra-plate events. It was, however, a difficult procedure to identify the geometry of the fault plane that caused the main-shock until enough number of aftershocks have been observed. Both southwestern and northeastern dipping planes could explain observed seismic waveforms (Yamanaka, 2004).

In this study, we try to constrain which nodal plane is the fault of the main-shock, using the precise pressure gauge dataset from the off Muroto cabled observatory. First we carry out tsunami computation, using two different fault models, i.e., SW- and NE-dipping faults. Then we see which one is a suitable model to explain the observed pressure waveforms in the offshore. Since we do not need to consider the effects of non-linearity of shallow water bathymetry for offshore pressure gauges, the location of the pressure gauge stations, and the response of the pressure gauges could directly be used in the numerical computation. Offshore tsunami waveforms obtained by pressure gauges show more reliable and have higher quality than that classically obtained at the coast as reported by Tanioka et al. 


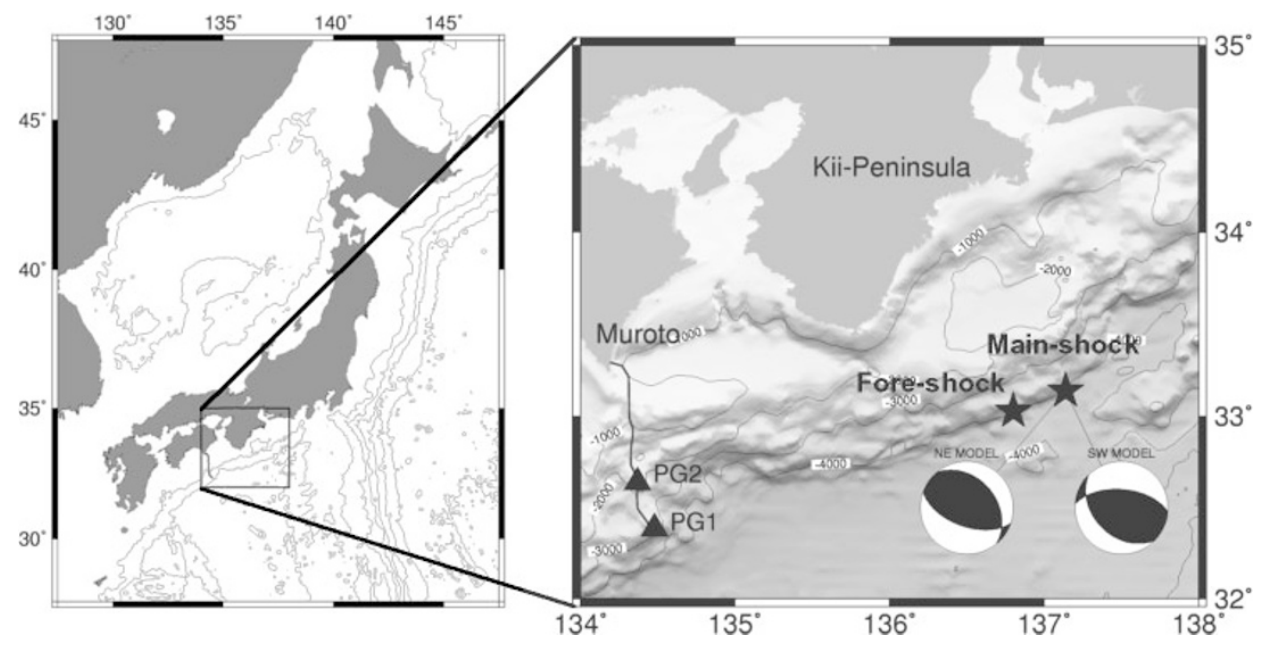

Fig. 1. Location of the epicenter of the 2004 off the Kii peninsula earthquakes. Stars indicate the epicenters of the fore- and the main-shocks. Triangles represent the ocean-bottom pressure gauges in the off Muroto cabled-observatory system, which are connected with the optical fiber cable. Two focal mechanisms of the main-shock are estimated by Yamanaka (2004), the left one is initially proposed dipping toward northeast, the right one is later-modified dipping toward southwest.

(2004). Baba et al. (2005) and Satake et al. (2005) also used the pressure gauges' dataset obtained off Muroto in addition to some coastal tide gauges' records in order to evaluate the tsunami source area at the event. The results obtained in this study demonstrate that the method could be combined with existing methods to obtain focal mechanisms and that offshore pressure dataset be exploited to see which of two nodal lines is suitable for a seismic event. It was also confirmed that tsunami signals arrived at the pressure gauge stations $20 \mathrm{~min}$ in advance to the arrival to the shore. We think that offshore pressure gauges would be of use to provide both additional information to earthquake monitoring and leading time to real-time tsunami monitoring.

\section{Records of Pressure Gauges}

Two PGs, PG1 and PG2 are deployed at the water depth of $2340 \mathrm{~m}$ and $1555 \mathrm{~m}$, respectively. Each of the PGs uses a quartz pressure sensor and its relative resolution is approximately $0.3 \mathrm{hPa}$, which is equivalent to $0.3 \mathrm{~cm}$ in the static water column, if the final sampling speed is set at $1 \mathrm{~Hz}$ (Hirata et al., 2002). These PGs are located approximately ca. $250 \mathrm{~km}$ from the epicenters (Fig. 1). Tsunami energy must propagate mainly to SW and NE directions, because the seismic fault of the main-shock strikes NW to SE direction.

Figure 2 shows the acquired pressure waveforms during the fore- and the main-shocks at PG1 and PG2. Significantly high-amplitude water pressure fluctuations were observed at the time of the earthquakes because of the disturbances due to incident seismic waves. Since the acquired water pressures contain these high-level noises during the earthquakes, we attempt to remove the noises in the application of moving average at $60 \mathrm{~s}$ to the original dataset. The same procedure to remove seismic noise and to detect tsunami signal has been done by Hino et al. (2001) for a dataset from a cabled observatory at the off Sanriku earthquake in 1998. The two time series of water pressures during the fore- and the main-shocks at PG1 and PG2 thus

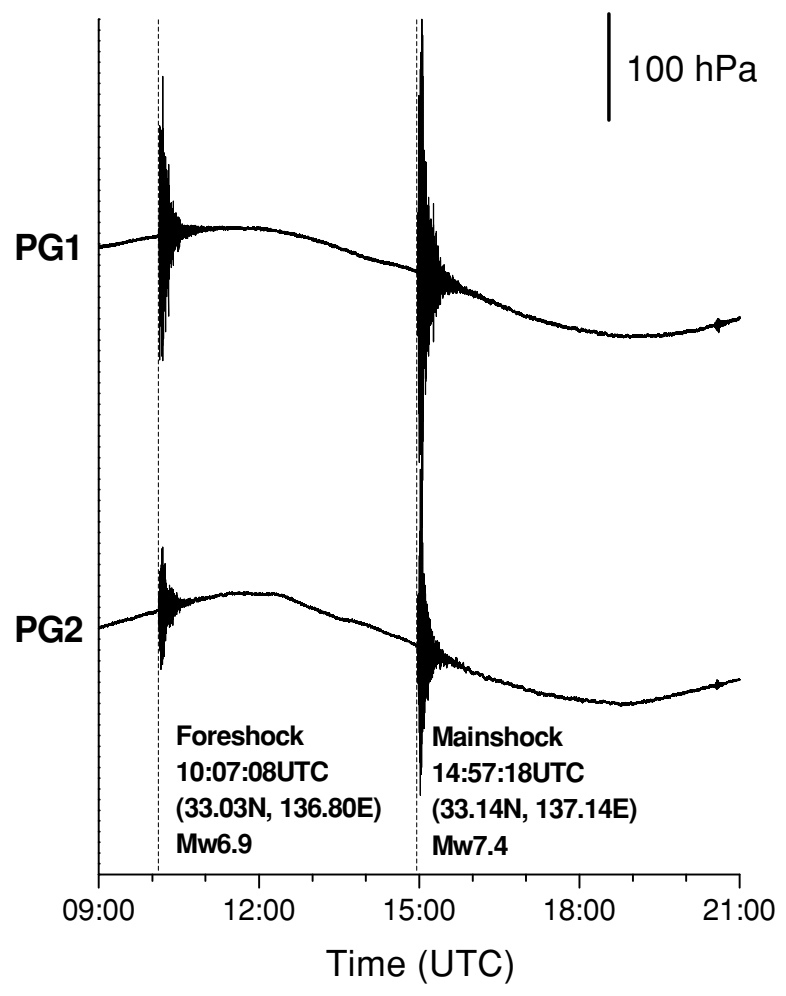

Fig. 2. Pressure fluctuations at PG1 and PG2 during the series of the 2004 off the Kii peninsula earthquakes. The precursory shock occurred at 10:07:08 UTC with its moment magnitude Mw 6.9, followed by the Mw 7.4 main-shock at 14:57:18 UTC. Full water pressure waveforms have been recorded during the earthquakes.

obtained are shown in Fig. 3. Although the observed waveforms are still accompanied by large amplitude tidal waves and high frequency seismic pressure vibrations, tsunami components are clearly visible in the waveforms. It is difficult to decompose tsunami signal only from the dataset particularly due to seismic waves in the case of the nearfield event (Hino et al., 2001; Hirata et al., 2003), but longperiod signals that could be regarded as tsunamis with pe- 


\section{(a) Fore-shock}

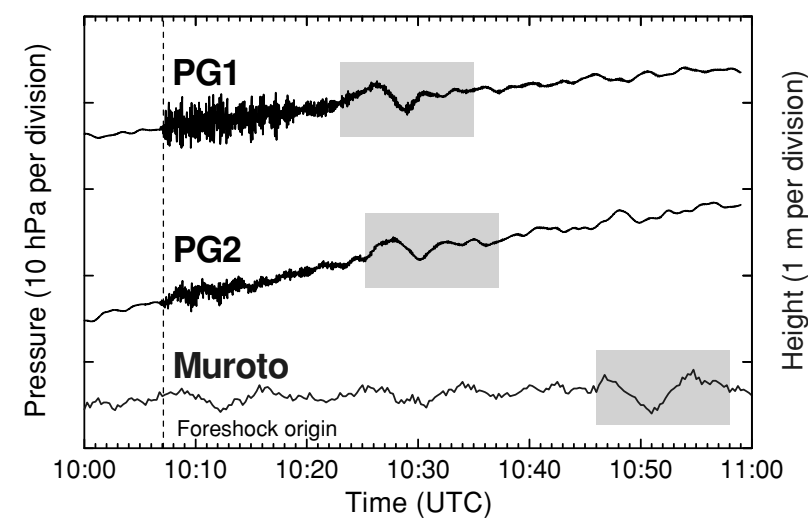

(b) Main-shock

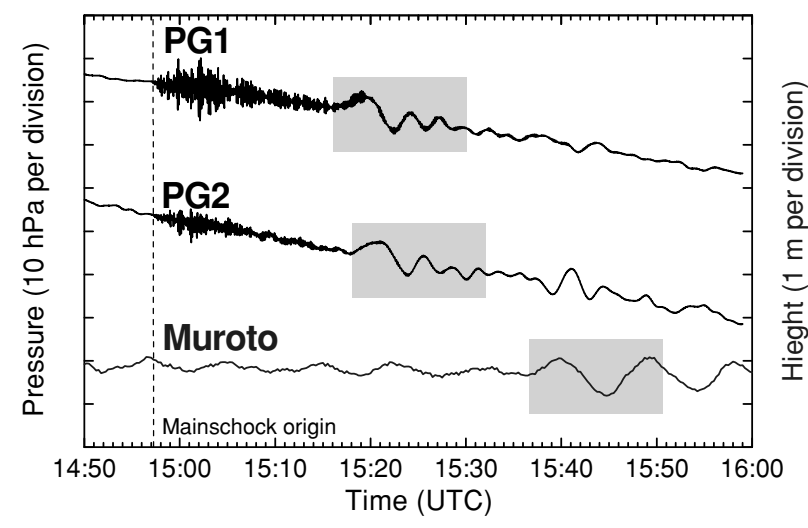

Fig. 3. Water pressure waveforms after applying the moving-average at $60 \mathrm{~s}$ (black lines) for (a) the fore-shock and (b) the main-shock (in hecto-pascal). Tidal waveforms at Muroto (blue lines) are also shown (in meter). Vertical dashed lines represent the origin time of the earthquakes. Shaded regions represent the first arrival tsunami detected. The first tsunami arrived at the offshore pressure gauges at 10:23 and 15:16 for the fore- and the main-shocks. The amplitude of tsunami by pressure gauges is less than $10 \mathrm{hPa}$ (ca. $10 \mathrm{~cm}$ in water level), while the tsunami amplitude at Muroto is $0.5 \mathrm{~m}$ to $1 \mathrm{~m}$ by amplifying at the coast.

riods of approximately $6 \mathrm{~min}$ and $7 \mathrm{~min}$ at the fore- and the main-shocks, respectively, were derived in the waveforms. If we apply a low-pass numerical filtering at $100 \mathrm{~s}$ to the originals, the amplitude as well as the arrival time of the tsunami component is similar to the moving-averaged one, while the seismic noises could be more attenuated. We use, however, the current averaging method to minimize the effects of leaking energy in the application of zero-phase digital filters. We perceive that the first tsunami signals arrived at 10:23 and 10:25 at the PG1 and PG2, respectively for the fore-shock and at 15:16 and 15:18 at the PG1 and PG2, respectively, for the main-shock. We could detect the first tsunami arrivals for ca. 20 min after the origin time of the earthquake. According to JMA, the first tsunami observed at 10:48 and 15:37 at Muroto, i.e., the nearest tidal gauge station to the PG2, that is ca. 40 min after the earthquake (Fig. 3). Thus, the cabled observatory could detect the first tsunami 20 min before the arrival at the coast station. For both the PGs, the tsunami begins with a flood motion. Peak-to-trough amplitudes of the observed tsunamis are to be approximately $4 \mathrm{hPa}$ and $7 \mathrm{hPa}$ at the fore- and the main-shocks for both PGs after the application of a $60 \mathrm{~s}$ moving-average to the originals. Since $1 \mathrm{hPa}$ in water pressure change corresponds to $1 \mathrm{~cm}$ in static water column, the observed peak-to-trough tsunami amplitude at the spots where PGs deployed could be estimated to be ca. $4 \mathrm{~cm}$ and $7 \mathrm{~cm}$ at the fore- and the main-shocks, respectively, while the tide gauge at Muroto recorded peak-to-trough tsunami amplitude of about $0.5 \mathrm{~m}$ and $1 \mathrm{~m}$ at the fore- and the mainshocks, respectively.

\section{Tsunami Computations}

We computed pressure waveforms with assuming two different fault strikes, one is southwest-dipping fault and the other is northeast-dipping fault as is inferred from the focal mechanism (Fig. 1). Two models were chosen in the least square criteria to simulate seismic waveforms (Yamanaka, 2004). The SW- and NE-dipping fault models have $135^{\circ}$ strike, $40^{\circ}$ dip angle, and $123^{\circ}$ slip angle, and $320^{\circ}$ strike, $57^{\circ}$ dip angle, $115^{\circ}$ slip angle, respectively. The location of the epicenters are collocated at the same place at $33.14^{\circ} \mathrm{N}, 137.14^{\circ} \mathrm{E}$, for the both models. We assumed the uppermost edge of the fault planes to be $0.1 \mathrm{~km}$ for the both models. The effective seismic faults are segmented into totally 28 sub-faults, 7 segments for the strike direction and 4 segments for the dip, in which each evaluated slip is given in such a way of the heterogeneously slip distribution based on Yamanaka (2004). Although Yamanaka (2004) also evaluated the variation of the slip direction for each sub-fault, we fixed the direction of the slip constant over the entire fault plane of the models except for the shallower part of the SW-dipping fault model, i.e., the slip angle $115^{\circ}$ for the entire NE-dipping fault and $123^{\circ}$ for 21 deeper segments and $141^{\circ}$ for 7 shallowest segments of the SW-dipping fault. Therefore, a strike slip motion dominates in the shallower part of the SW-dipping fault. The SW-dipping fault has the maximum slip of $6.5 \mathrm{~m}$ near the epicenter, while the NEdipping fault has the maximum slip of $5.7 \mathrm{~m}$ near the shallower part. Although Yamanaka (2004) estimated the detailed rupture process, i.e., the propagation of the seismic faulting, we used only static co-seismic deformation of the ocean-bottom derived by the given slip distribution over the assumed fault models, because our main aim is to constrain the fault geometry from the offshore tsunami waveforms. A dislocation theory proposed by Kataoka (1999) is used to compute the static deformation of the ocean-bottom. Maximum uplifts were estimated as $150 \mathrm{~cm}$ near the epicenter for both the models, while the subsidence in NE-dipping fault is larger than that of SW-dipping one (Fig. 4).

For the tsunami computation, we carried out the dynamic tsunami modeling developed by Ohmachi et al. (2001), in which the initial condition of the tsunami excitation caused due to dynamic motion of the ocean-bottom. Compressible ocean water as well as absolutely rigid ocean-bottom is assumed in the tsunami computation. We also computed the tidal wave using a method introduced by Matsumoto et al. (2000), and added it to our synthetic pressure waveform calculations. For building the synthetic waveforms, we use the static vertical deformation of the ocean-bottom computed above, and provide it to the bottom of water layer 
(a) SW-Dipping

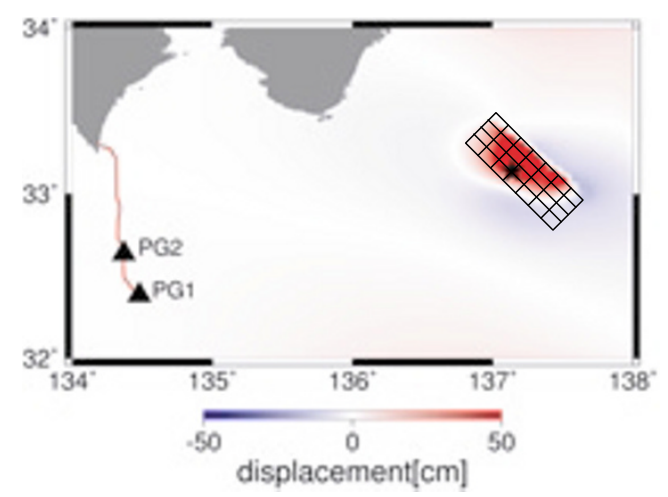

(b) NE-Dipping

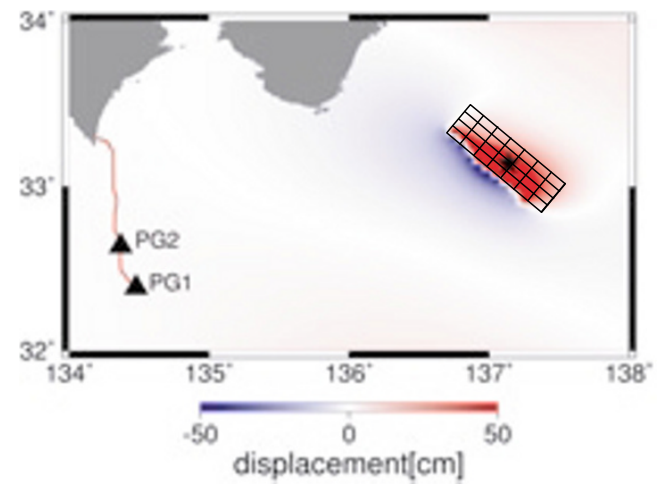

Fig. 4. Comparison of vertical static deformation patterns caused by the earthquake in the case of (a) the SW- and (b) the NE-dipping faults. Red and blue colors represent the sense of uplift and subsidence, respectively. Projection of the sub-faults on which the solid-star marks the epicenter of the main-shock is also shown.

as a ramp-time function with a 30 s rise-time as in the estimation of source-time function of the earthquake by Yamanaka (2004). Although more realistic seismic source space-time functions may be employed in the computation, there is no difference in the simulated results for the tsunami component caused by the seismic faulting with its source time function of $30 \mathrm{~s}$ duration time (Matsumoto et al., 2004). Hence, this approximation is appropriate. To calculate water pressure, a finite different method of the Navier-Stokes equations is numerically solved in terms of the SOLA method (Hirt et al., 1975). The grid sizes are $1 \mathrm{~km}$ and $0.5 \mathrm{~km}$ in horizontal and vertical directions, respectively. These grid sizes are appropriate for the far-field tsunami waveforms, because water compressibility related to tsunami propagation is not so significant (Ohmachi et al., 2001). The time step for the computation is 0.25 s to satisfy the stability criteria of the finite difference modeling.

The synthetic pressure fluctuations from the two fault models are compared to the observations at PG1 and PG2 (Fig. 5). At the beginning of the simulated pressure fluctuations, two visible pulses appeared. These large amplitude pulses are produced by the acoustic effects at the beginning and the end of the rupture time due to very small deformation (less than $1 \mathrm{~cm}$ ) at the PG1 and PG2 locations introduced by the assumed fault models. These small deformations at PG1 and at PG2 generate small tsunamis as well, which propagates with very minor amplitudes negligible in the present numerical simulation. Small amplitude fluctuations, which are computed at 15:02 for both PG1 and PG2, are the results of the tsunami propagated from the vicinity of the epicenter. Although both the synthetic waveforms derived from the two fault models show little pressure fluctuations from the tide level before the first peak, the arrival of the peaks are much different from each other. The amplitude difference is also visible in the synthetic waveforms, i.e., a negative lobe of the NE-dipping fault model larger than that of the SW-dipping one. This difference in the negative lobes is derived from that of the co-seismic subsidence patterns for which NE-dipping model provides larger subsidence of the seafloor in an area between the fault plane and the pressure gauges than the SW-dipping one (Fig. 4). The

\section{(a) PG1}

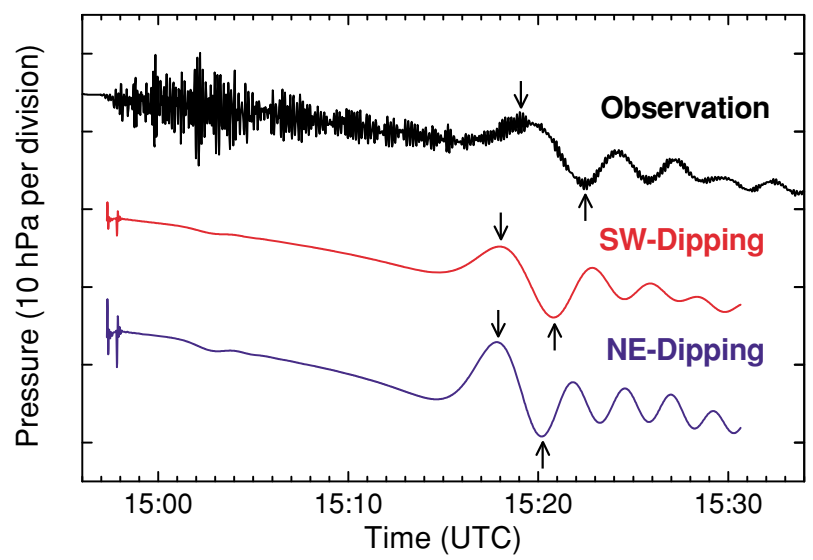

\section{(b) PG2}

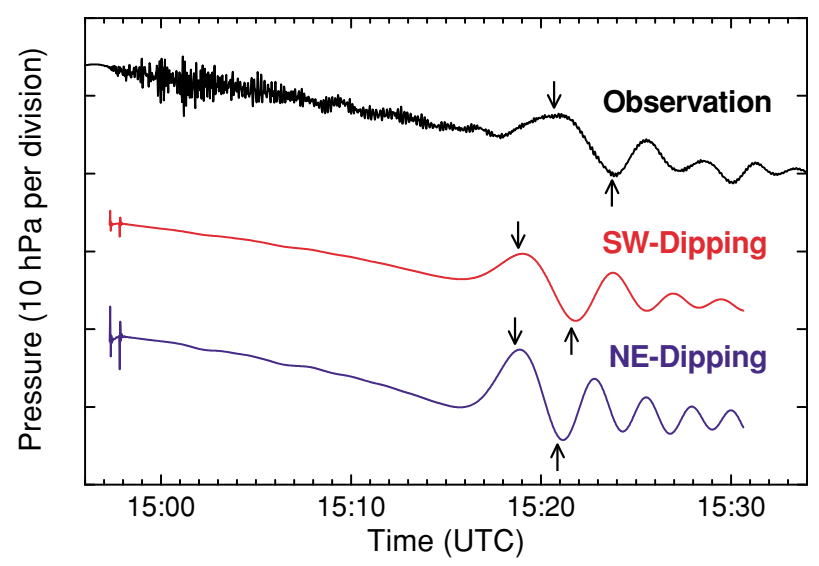

Fig. 5. Comparison of the observed and computed pressure waveforms at (a) PG1 and (b) PG2. Red and blue lines represent the synthetic waveforms from the SW- and the NE-dipping fault models. Downward- and upward-arrows respectively indicate the first peak and the first trough of the tsunami signal. 
synthetic amplitudes of the tsunami components of the SWdipping and NE-dipping faults are ca. $9 \mathrm{hPa}$ and $12 \mathrm{hPa}$, respectively. The SW-dipping one is closer to the observations of $7 \mathrm{hPa}$. The first peaks of two models denoted by the downward arrows in Fig. 5 arrive at 15:18 and at 15:19 for PG1 and PG2, respectively. These arrivals are 1 to $2 \mathrm{~min}$ earlier than in the observations. The first troughs (the most negative motion) denoted by the upward arrows follow the first peaks. Although the arrival times of the first troughs of the two models still misfit to the observations with a time difference in a few minutes, the synthetic arrival time of the $\mathrm{SW}$-dipping fault is closer to the observed one. Time durations between the first peak-to-trough in the observation, i.e., a half of period of the tsunami are $3 \mathrm{~min}$ at PG1 and PG2. Those of SW- and NE-dipping faults are computed to be $3 \mathrm{~min}$ and $2 \mathrm{~min}$, respectively. Because the period of the tsunami strongly depends on the fault size projected on a horizontal plane, $1 \mathrm{~min}$ discrepancy in the period between two models is caused by the difference of dip angle of the seismic fault planes. As for the later phase waveforms, the phase of the synthetics is not consistent with the observations. This may be due to a misfit in the assumed source-time function to the seafloor uplifts and needs be investigated into more detail. Comparisons of the observed and synthetic pressure waveforms suggest that a better fit of the fault plane results in the SW-dipping one than the NEdipping one with respect to the tsunami amplitude and its period, although there are still discordances which remain between the observations and synthetics for the tsunami arrival time and later phases.

\section{Conclusions}

We have reported that two pressure gauges off Muroto successfully recorded water pressure fluctuations for a foreshock and a main-shock of the off Kii peninsula earthquake which took place on September 5 2004. Since it is difficult to identify seismic fault for the main-shock from its focal mechanism of a NW-SE strike thrust fault earthquake, we have computed the pressure waveforms in the offshore for two seismic fault models of the main-shock. The two fault models with a SW- and a NE-dipping planes, can both reproduce observed seismic waveforms, and two sets of tsunami waveforms for these models are computed at the two pressure gauge locations to see which model is suitable to explain observed tsunami signals. Since the NE-dipping fault reproduced shorter period as well as larger amplitude tsunami waveforms than the SW-dipping fault, mainly due to the fault dip angle, our result implies that the fault geometry of the main-shock should strike NW-SE direction with SW-dipping. The synthetics from the SW-dipping fault could explain the period of the later phases as well. Thus, we demonstrated that the dataset recorded by the pressure gauges in the offshore has reinforced the fault geometry of the earthquake. Although there are still discrepancies with respect to the tsunami arrival time between the observed and synthetic waveforms in the SW-dipping fault model, the earlier misfits in the synthetics compared to the observed may be resolved if the fault plane location is further eastward, i.e., the further distance is required between the fault plane and the observatories.
Detailed aftershocks' distribution examined by the ocean-bottom seismometers, OBSs installed in the source area, and precise co-seismic deformation on land measured by the dense Global Positioning System, GPS networks may be common and well known evidences in order to understand and improve the fault mechanism (e.g., Hashimoto et al., 2005). Although the number of the permanent observatories of pressure gauges offshore is now very few, about 10 instruments installed around Japan, they could be used as a constraint to identify a fault plane from two nodal planes in the source mechanism of off-shore earthquakes. Since high-precision water pressure measurements on the seafloor in the offshore detected the tsunami ca. 20 min before the arrival to the shore for the studies earthquake that took place beneath the central Nankai seismogenic zone, it might be proven that the offshore real-time monitoring system off Muroto has a potential to be used in the tsunami disaster mitigation at the forthcoming Tonankai earthquake that could take place near the present tsunami sources.

Acknowledgments. We used pressure gauges' dataset distributed by Submarine Cable Data Center, Japan Agency for Marine-Earth Science and Technology. Tide gauge record at Muroto was provided by Japan Meteorological Agency. We are grateful to Ryota Hino and an anonymous reviewer for their discussions and suggestions to the manuscript. We thank Tatsuo Ohmachi and Shusaku Inoue at Tokyo Institute of Technology for their collaborations. We computed the static displacement of the ocean-bottom by using the FEM-BEM coupled code made by Shojiro Kataoka at National Institute for Land and Infrastructure Management. We used generic mapping tools (Wessel and Smith, 1995) to make some figures in this paper.

\section{References}

Baba, T., P. R. Cummins, and T. Hori, Compound fault rupture during the 2004 off the Kii Peninsula earthquake ( $M$ 7.4) inferred from highly resolved coseismic sea-surface deformation, Earth Planets Space, 57, this issue, 167-172, 2005.

Hashimoto, M., K. Onoue, F. Ohya, Y. Hoso, K. Segawa, K. Sato, and Y. Fujita, Crustal deformations in Kii peninsula associated with the SE off the Kii peninsula earthquake sequence of September 5, 2004 derived from dense GPS observations, Earth Planets Space, 57, this issue, 185190, 2005.

Hino, R., Y. Tanioka, T. Kanazawa, S. Sakai, M. Nishino, and K. Suyehiro, Micro-tsunami from a local interplate earthquake detected by cabled offshore tsunami observation in northeastern Japan, Geophys. Res. Lett., 28, 3533-3536, 2001.

Hirata, K., M. Aoyagi, H. Mikada, K. Kawaguchi, Y. Kaiho, R. Iwase, S. Morita, I. Fujisawa, H. Sugioka, K. Mitsuzawa, K. Suyehiro, H. Kinoshita, and N. Fujiwara, Real-time geophysical measurements on the deep seafloor using submarine cable in the southern Kurile subduction zone, IEEE J. Ocean. Eng., 27, 170-181, 2002.

Hirata, K., H. Takahashi, E. Geist, K. Satake, Y. Tanioka, H. Sugioka, and H. Mikada, Source depth dependence of micro-tsunamis recorded with ocean-bottom pressure gauges: The January $28,2000 \mathrm{M}_{\mathrm{W}} 6.8$ earthquake off Nemuro Peninsula, Japan, Earth Planet. Sci. Lett., 208, 305318, 2003.

Hirt, C. W., B. D. Nicholas, and N. C. Romero, SOLA-A numerical solution Algorithm for transient fluid flow, Rep. Los Alamos Scientific Laboratory (LA-5852), 1975.

Kataoka, S., A 3-D FE-BE method for dynamic response analysis of damfoundation-reservoir systems, Proc. 2nd U.S.-Japan Workshop on Advanced Research on Earthquake Engineering for Dams, 347-354, 1999.

Matsumoto, H., H. Mikada, T. Ohmachi, and S. Inoue, Tsunamis caused by slow seismic fault rupturing, Ann. J. Coast. Eng. JSCE, 51, 281-285, 2004 (in Japanese).

Matsumoto, K., T. Takanezawa, and M. Ooe, Ocean tide models developed by assimilating TOPEX/POSEIDON altimeter data into hydrodynamical model: A global model and a regional model around Japan, $J$. 
Oceanography, 56, 567-581, 2000.

Ohmachi, T., H. Tsukiyama, and H. Matsumoto, Simulation of tsunami induced by dynamic displacement of seabed due to seismic faulting, Bull. Seism. Soc. Am., 91, 1898-1909, 2001.

Satake, K., T. Baba, K. Hirata, S. Iwasaki, T. Kato, S. Koshimura, J. Takenaka, and Y. Terada, Tsunami source of the 2004 off the Kii Peninsula earthquakes inferred from offshore tsunami and coastal tide gauges, Earth Planets Space, 57, this issue, 173-178, 2005.

Tanioka, Y., K. Hirata, R. Hino, and T. Kanazawa, Slip distribution of the 2003 Tokachi-oki earthquake estimated from tsunami waveform inversion, Earth Planets Space, 56, 373-376, 2004.
Watanabe, T., H. Matsumoto, H. Sugioka, H. Mikada, K. Suyehiro, and R. Otsuka, Offshore monitoring system records recent earthquake off Japan's northernmost island, EOS Trans., 85, 14, 2004.

Wessel, P. and W. H. F. Smith, New version generic mapping tools (GMT) version 3.0 released, Eos Trans. AGU, 76, 329, 1995.

Yamanaka, Y., Offshore Southeast of the Kii Peninsula Earthquakes, EIC Seismological Note, 152 and 153, 2004 (in Japanese).

H. Matsumoto (e-mail: hmatsumoto@jamstec.go.jp) and H. Mikada 